THURSDAY, FEBRUARY $19, \quad 1885$

\section{A SCIENTIFIC VIEW OF THE COAL QUESTION}

$\mathrm{I}^{\mathrm{T}}$ is well known that our stock of coal is not an infinite quantity, and cannot last an infinite period of time. Different authorities, and those who have investigated the subject, including a Royal Commission, have assigned different lengths of time during which our supply is likely to last ; and, according to the most reliable authorities, it cannot be much less than roo nor much more than 250 years.

Our abundant store of coal, and its application to industrial purposes, has been one of the largest causes of our wealth and progress. The value of coal for those purposes depends essentially upon, the fact that it is combustible, and evolves a large amount of heat in burning, and that this heat can be set free at any time and be readily converted into mechanical, chemical, electrical, and other forms of power. As an illustration of the great amount of energy contained in coal, it is well known to scientific men that each piece of it contains sufficient stored-up power to lift its own weight 2300 miles in height, or 2300 times its own weight a mile high. The only other common natural substances to be compared with it in this respect are wood and petroleum, and our stores of these are very small. It is by the expenditure of the energy contained in coal that comparatively valueless iron ore is converted into valuable iron.

It has not been by the mere existence of large quantities of coal in this country, nor entirely by the sale of coal to foreign nations, that so much of our wealth has been obtained, but largely by the circumstance that we were the first nation to apply coal to industrial purposes on a large scale and in a great variety of ways. Other nations also possessing coal, perceiving the great success of this method, followed our example, have overtaken us, and have now rendered it increasingly difficult, year by year, for us to maintain our position as manufacturers.

As also large quantities of coal, petroleum, and inflammable gas are continually being discovered and utilised in other countries, and it is known that the United States of America alone contain nearly forty times as much coal as our entire stock, the time cannot be very far distant when our chances of maintaining even our present position amongst nations by means of our coal will be considerably less than at present. It would be wise, therefore, boldly to face this serious prospect, and consider by what means our national prosperity can be maintained as our coal diminishes in quantity and increases in price, cspecially as our population is continually increasing, and require to purchase greater supplies of foreign food.

There does exist another and inexhaustible source of wealth and progress, viz. new knowledge obtainable by means of scientific research. It is upon such knowledge, gained by experiments made to examine natural forces and substances, that we must sooner or later depend as a fundamental source of national prosperity. As fast as this knowledge is evolved by discoverers, it is applied in more immediately practical forms by numerous inventors, and then manufacturers and men of business use those VOL. Xxxi.-No. 799 practical realities in the production of wealth. This has been the order of events in the past, and will be in the future; this was the way in which we got wealth out of coal. Persons of narrow views on the subject will consider the above proposition vague and unpractical, but this order of things is a great fact and unavoidable; we are the servants of nature, and have no choice in the matter; we might as well hope to live without food as expect to advance in civilisation without the aid of new knowledge.

The practical value of new scientific knowledge as a source of wealth and progress is incomparably greater than that of all the coal-deposits, petroleum springs, and gold-fields of the earth. This great truth, though familiar to scientific investigators, is but little perceived or appreciated by our rulers, or by the mass of their electors ; and the chief reason for this is the fact that they possess insufficient knowledge of science. Even Governments can only appreciate that which they understand, and can only act as circumstances and public opinion allow them, and when fettered by an ignorant population, are powerless to preserve a nation from decay.

There cannot be a more complete error than to suppose that new knowledge discovered by means of scientific research is not practical. Its immense practical value has been abundantly proved in a multitude of cases. It was largely by means of such knowledge respecting coal, its properties, constituents, and products, gained by means of experiments, that coal was applied to so many uses. One of the most recent proofs of the practical value of such knowledge is the conversion of the heat of coal into electric current and light in the dynamo-electric machine and electric lamp; the entire existence of these instruments arose from new knowledge discovered in purely scientific researches by Davy and Faraday. It is not necessary to describe here the exact beginnings of gaslighting, phosphorus-matches, photography, the voltaicbattery, electro-plating, aniline dyes, telegraphy, the telephone, \&c. ; these, and a multitude of other utilities in common use, had their earliest origin more or less completely, not in the labours of the inventor or of the more directly practical man, but in those of philosophical inves. tigators whose experiments were made with the far more widely practical object, the discovery of new scientific knowledge.

It is not the mere possession of good things, but making the best and earliest use of them that most conduces to success. Our great stock of coal lay comparatively useless as a source of national wealth unti[ philosophical investigators discovered its constituents and properties, and inventors applied these to useful purposes; other nations also possessed coal, and our greater success than theirs was largely and essentially due to the fact that we were the earliest in applying it to important and varied uses. We must not wait, therefore, for those nations to discover for us new knowledge respecting natural forces and substances, but discover it ourselves, in order that we may have the first chance of applying those forces and substances to practical uses, and of offering the useful products for sale or in exchange for food and other commodities.

It is well known that a man who has no faith in medicine will not apply to a physician until death stares him 
in the face. Similarly, the average politician and the ordinary elector, having but little knowledge of philosophical experiments, or faith in them, will probably not believe in their great practical value until national distress and panic legislation ensue. The love of money also, and the desire of acquiring it quickly without commensurate sacrifice, fostered by our having so easily obtained it by means of our coal and science, is so strong in this nation, that probably nothing but the actual loss of wealth in the form of diminished value of properties, will induce capitalists and land-owners to perceive and examine the scientific basis of their incomes. When, however, the stern reality of gradually increasing scarcity of coal, and consequent inability to pay for our great supplies of foreign food by means of that coal, and of articles produced by its aid, comes upon us, perhaps the statesmen and wealthy classes of this country will see the indispensable necessity of new scientific knowledge, and be more ready to promote experimental research, with a conviction that its practical results are vast, though not always direct or immediate.

G. GORE

\section{MAMMALIAN DESCENT}

On Mammalian Descent; the Hunterian Lectures for I884. By W. Kitchen Parker, F.R.S. (London: Griffin and Co., I885.)

$\mathrm{A}^{\mathrm{S}}$ far as we are aware, no attempt has hitherto been A made to popularise in any detail the science of comparative embryology. It is therefore indicative of the characteristic originality of Prof. Parker that, on delivering a course of Hunterian lectures upon the embryology of the Mammalia, he should have aimed at charming a popular audience as well as at instructing a scientific one. We confess that upon reading the first paragraphs of his preface, in which he states his intention of handling his subject in a popular way, we felt apprehensive that, like sundry other lecturers with a similar aim and with subjects better suited to the killing of two birds with one stone, he was preparing for himself the misfortune of missing both his marks. But we had not got far into the first lecture without finding that our lecturer very well kncw what he was about : he is provided with a double-shotted weapon of the most modern construction, and takes a genuine glee in knocking over some antediluvian toothbearing bird on the one side, and the sentimental scruples of a nineteenth-century audience upon the other. And this is done with so much of the vigour of enthusiastic science, as well as the genuine fceling of what we may term unspoiled poetry, that we feel our thanks are clue to Miss Arabella Buckley who, it seems, first persuaded Prof, Parker to adopt this delightful method of writing. Moreover, it is obviously to him a natural method. We can everywhere see that he is now writing in the lines of his habitual thinking. The smallest details of his science catch a living glow from the ardour of his imagination, and as this imagination is cverywhere charged with biblical thoughts and biblical metaphors, we are led by the force of example to compare it to some quickening spirit which makes all the dry bones of the skulls and skeletons stand up around him as an excceding great army. Well it is for the cause of evolution that in Prof. Parker it has not only so indefatigable a worker, but likewise so ele- vated a preacher; and being thus as strong a champion on the side of sentiment as he is on that of science, we have only to congratulate him upon the wisdom of adopting Miss Buckley's advice, and appearing in the lists armed with the weapons of feeling as effectually as with those of fact.

The course consists of nine lectures, and there are, besides, extensive addenda. In the 229 pages to which the book runs, we have presented an excellent epitome of the author's work on the embryology of the Mammalia. The perusal of this epitome cannot fail to strike us anew with admiration at the prodigious amount of his labours, and the great results which they have accomplished. When future generations come to survey the work done by the contemporaries of Charles Darwin in establishing the doctrine of evolution, and in beginning the great task of tracing out the main lines of descent in the animal kingdom, the name of Parker will stand out as one of the most conspicuous of the landmarks.

Two or three quotations from the present volume will serve to convey a general idea of the style, upon which we have laid so much stress. Speaking of a remarkable proboscidian Insectivore, about the size of a rat (Rhynchocyon cernei), a ripe embryo of which he has obtained from near Zanzibar, the lecturer says :-

"I have, at present, merely worked out the skull of this valued specimen, but it has rewarded and delighted me more than any kind I have reccived for a long time past. If nature had titurated together the germs of four or five types of mammals, and had then made this mixture grow, she could scarcely have developed a more curious and composite creature than this long-nosed Insectivore. When Prof. Huxley propounded his oft-quoted theory of the evolution of the Mammalia, he might have known the structure and development of this type by inward sight. Nothing of the kind, however, is ever revealed to biologists in this manner, we only get our facts by opening out the fine folds of organic forms with needle and scissors; we do unroll a good number of the small scrolls, but it is painful and patient work. I am satisfied that no searcher after the evidences of evolution ever saw anything more instructive than what $I$ have found in this small beast. I will make a catalogue of its characters... . Thus this greatly specialised kind of Insectivore, whilst retaining the most marked characteristics of the Metatherian skull, takes on two characters, one of which, had it become dominant, would have landed it amongst the Proboscidea, or elephants, whilst the other would have made it a Carnivore. It attempted too much at once, and thus, like a man in doubt, it made but little progress; moreover, in this developmental shilly-shallying, it failed to drop the Marsupial, to take on the new Eutherian, nature, and was thus in danger of going out of being with many of the members of that much-extinguished type. Other types, not thus confused in their ambition, worked out the old strain of Metatherian degradation, and, taking to one definite line of ascent, put on new specialisations in harmony with their surroundings, and to this day their descendants are the rulers of the forest and the field."

\section{Again :-}

"Supposing the theory of the slow secular transformation of the old general types into new special types to be true, then the existing mole, in its perfection of adaptive structure, has been as long in coming to its present perfection as the larger and nobler prone or erect types that trample the earth over its head. In its own line, doing its own dark work, it is as complete a creature as the clear-eyed, super-terrestrial types; as a mole, it is con- 